\title{
Mixed-Lineage Leukemia Fusions and Chromatin in Leukemia
}

\author{
Andrei V. Krivtsov, Takayuki Hoshii, and Scott A. Armstrong \\ Department of Pediatric Oncology, Dana Farber Cancer Institute, and Division of Hematology/Oncology, \\ Boston Children's Hospital, Boston, Massachusetts 02215 \\ Correspondence: scott_armstrong@dfci.harvard.edu
}

Recent studies have shown the importance of chromatin-modifying complexes in the maintenance of developmental gene expression and human disease. The mixed lineage leukemia gene (MLL1) encodes a chromatin-modifying protein and was discovered as a result of the cloning of translocations involved in human leukemias. MLL1 is a histone lysine 4 (H3K4) methyltransferase that supports transcription of genes that are important for normal development including homeotic (Hox) genes. MLL1 rearrangements result in expression of fusion proteins without $\mathrm{H} 3 \mathrm{~K} 4$ methylation activity but may gain the ability to recruit other chromatin-associated complexes such as the H3K79 methyltransferase DOT1L and the super elongation complex. Therefore, chromosomal translocations involving MLL1 appear to directly perturb the regulation of multiple chromatin-associated complexes to allow inappropriate expression of developmentally regulated genes and thus drive leukemia development.

\section{IDENTIFICATION AND STRUCTURE OF MLL} FUSIONS

Studies of acute leukemias carrying chromoSomal translocation of the long arm (q) of chromosome 11 at band q23 (11q23) (Rowley 1993) resulted in identification of the gene lysine methyltransferase 2A (KMT2A; also known as MLL, MLL1, HTRX, HRX, TRX1, ALL-1) (Ziemin-van der Poel et al. 1991; Tkachuk et al. 1992) as the recurrent target for these translocations. Subsequent studies have shown that MLL1/KMT2A mutations can result either in partial tandem duplications (MLL-PTDs) or in fusions with proteins functionally associated with active transcription (MLL fusions) (Domer et al. 1993; Gu et al. 1993; Prasad et al. 1994; Schichman et al. 1994; Chaplin et al.
1995). In this review, we will use MLL1/ KMT2A as the name for the gene and the more conventional and historical name "MLL fusions" or "MLL-PTDs" when referring to the protein generated by these chromosomal abnormalities.

More than $98 \%$ of breakpoints within the MLL1 gene are located within an 8.3-kb breakpoint cluster region between exons 8 and 13 (Meyer et al. 2013) that has multiple topoisomerase II cleavage sites as well as nuclear matrix attachment regions. Interference with normal cellular processes such as therapeutic inhibition of topoisomerase II leads to the formation of chromosomal rearrangements found in leukemia (Strissel et al. 1998). The rearrangements always result in either expression of an in-frame

Editors: Scott A. Armstrong, Steven Henikoff, and Christopher R. Vakoc

Additional Perspectives on Chromatin Deregulation in Cancer available at www.perspectivesinmedicine.org

Copyright (C) 2017 Cold Spring Harbor Laboratory Press; all rights reserved; doi: 10.1101/cshperspect.a026658 Cite this article as Cold Spring Harb Perspect Med 2017;7:a026658 
A.V. Krivtsov et al.

chimeric protein encoded by the first eight to 13 exons of KMT2A/MLL and a variable number of exons from the fusion partner gene or an aberrant KMT2A/MLL protein encoded by duplication of the first five to 12 exons of KMT2A/MLL inserted into exons 11 and 12 (Fig. 1) (Krivtsov and Armstrong 2007). Currently, more than 70 translocation partner genes have been reported; however, four (AF4, AF9, AF10, ENL) account for $>75 \%$ of cases (Meyer et al. 2013).

\section{MLL FUSIONS AT THE FOREFRONT OF LEUKEMIA RESEARCH}

Since their discovery, MLL fusions have been at the frontier of the leukemia research, likely because $M L L 1 / K M T 2 A$ rearrangements are quite potent oncogenes and require very few other, if any, secondary mutations to generate leukemia. This is in line with the natural history of MLL1rearranged leukemias that are one of the few mutations that generate leukemia in very young children including as early as a few days of life. Genetic "knockin" of AF9, a gene commonly found rearranged with $M L L 1$, into the Mll locus generated transgenic mice expressing the MllAF9 fusion protein product of $\mathrm{t}(9 ; 11)$ chromosomal translocation from the endogenous Mll1 promoter and formally proved that this oncogene can initiate acute myeloid leukemia (AML) and B-lymphoblastic leukemia (B-ALL), mimicking the human disease (Corral et al. 1996). Later, the same laboratory pioneered an elegant system in which interchromosomal Mll1 translocations could be induced in mice de novo and led to the development of acute leukemia (Collins et al. 2000; Forster et al. 2003).

A new avenue in the leukemia research was opened by ectopic expression of an MLL-ENL fusion protein in prospectively isolated hematopoietic stem cells (HSCs) and committed myeloid progenitor cells that resulted in similar AMLs (Cozzio et al. 2003). This experiment showed that MLL-ENL can reactivate hematopoietic self-renewal in committed myeloid progenitor cells called granulocyte-macrophage progenitors (GMPs). Previously, it was widely accepted that leukemogenic transformation originates only in HSCs (Dick 2005). Further- more, conditional expression of an Mll-Cbp fusion protein in hematopoietic cells led to expansion of GMPs before progression to fatal AML (Wang et al. 2005). Ectopic expression of MLLAF9 in GMPs followed by transplantation into syngeneic recipients resulted in AML with a relatively high leukemia stem cell frequency with approximately 1 in 150 cells being able to initiate disease in secondary recipient mice. Prospective isolation of leukemic cells (L-GMPs) with an immunophenotype similar to normal myeloid progenitors followed by transplantation into syngeneic recipients showed that leukemia initiating activity of this cell fraction was increased to $\sim 1$ in 6 . Microarray-based gene expression analyses showed up-regulation of a subset of genes in L-GMPs that are normally expressed in self-renewing HSC and suppressed during normal differentiation to GMPs. These genes are also highly expressed in human MLLrearranged AML as compared with other subtypes of AML, and we now know that many of these genes are direct binding targets of MLLfusion proteins. These studies showed that leukemia initiating cells do not necessarily have an immunophenotype similar to HSC and suggest that leukemia may be the result of expression of stem cell-associated genes in developmental cell types in which they should not be highly expressed (Krivtsov et al. 2006; Somervaille and Cleary 2006). A subset of the self-renewalassociated genes that are highly expressed in the majority of mouse and human MLL-fusion leukemias are the posterior HOXA cluster genes HOXA5-HOXA10 and the heterodimerizing partners of HOX proteins, MEIS1 and PBX3. The only known exceptions are the $\sim 10 \%$ of $t(4 ; 11)$ rearranged B-ALL that do not express HOXA cluster genes (Krivtsov and Armstrong 2007; Krivtsov et al. 2008).

Overall, these studies interrogating the biology of MLL1-rearranged leukemia have made a significant impact on the both the leukemia and hematology fields. In particular, the mouse model systems developed to study this leukemia continue to be used to study many aspects of leukemia biology. Furthermore, the detailed characterization of the gene expression programs driven by MLL-fusion proteins has pro- 
MLL Fusions and Chromatin in Leukemia

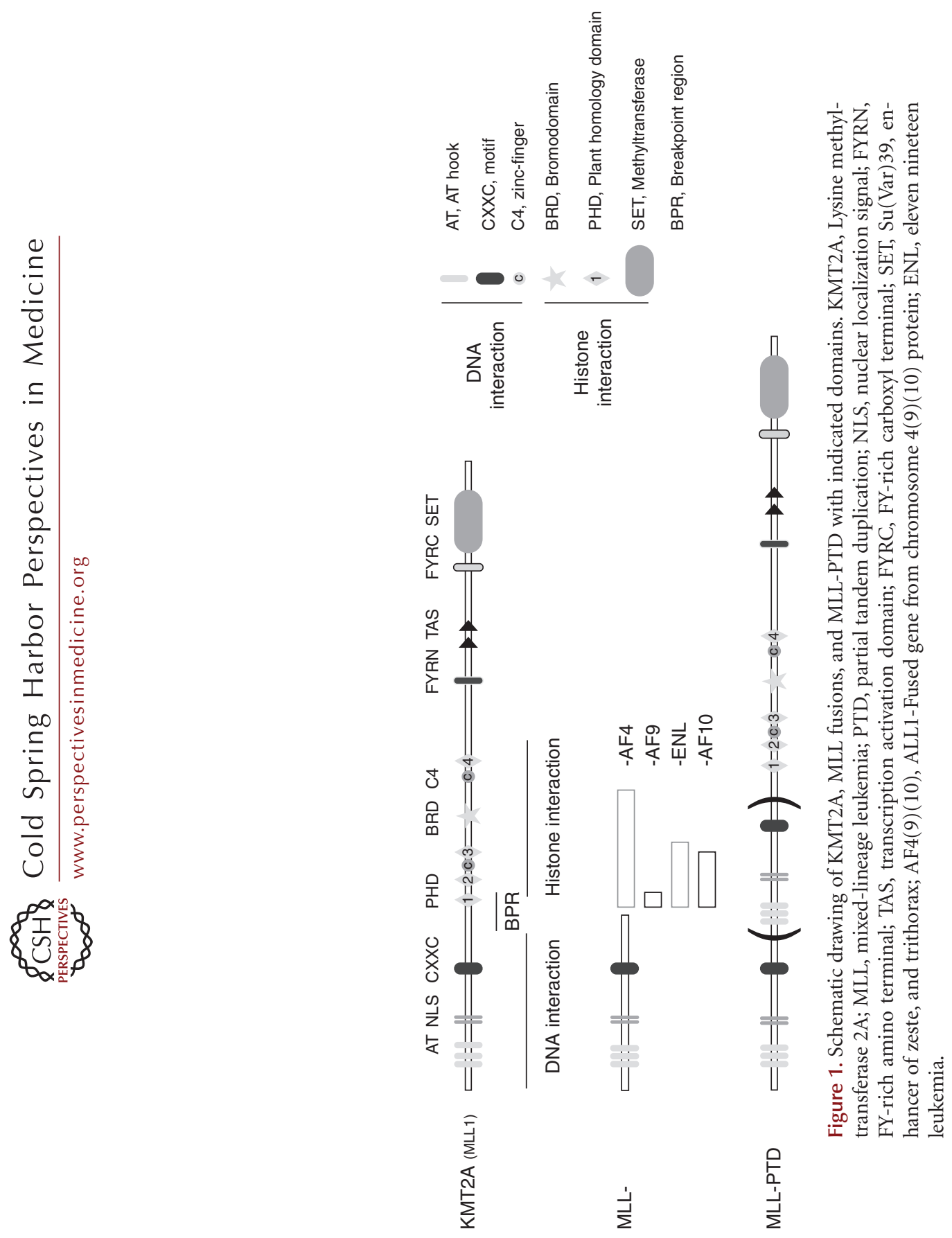


A.V. Krivtsov et al.

vided a foundation for studies that have focused on the molecular mechanisms of MLL1/ KMT2A and MLL-fusion protein function.

\section{STRUCTURE OF THE MLL/KMT2 FAMILY}

MLL1 (or KMT2A) is a member of the lysine (K) methyltransferase (KMT) 2 family of proteins that are highly conserved in eukaryotes most of which possess ( $\mathrm{Su}(\mathrm{var}) 3-9$, enhancer of zeste and trithorax) SET domains. Based on its protein domain composition, KMT2A's closest homolog is KMT2B (Fig. 2).

The MLL1 protein is a large nuclear protein that has multiple important well-defined domains. The amino terminus of MLL1 interacts with menin, a critical interaction for the MLLfusion protein function. This is followed by three AT-hook domains that can bind to the minor grove of DNA and a CXXC domain that binds to unmethylated CpGs (Rao and Dou 2015). The CXXC domain is followed by a set of domains that can interact with modified histone tails and includes four plant homology domains (PHDs) and a bromodomain (BRD). All MLL fusions include the MLL1 sequence up to, but not including, the PHDs. In fact, inclusion of PHDs within the MLL fusions negates the transformation activity of these fusions (Muntean et al. 2008). Full-length MLL1 is cleaved by Taspase 1 and reassembled through interaction of FYRN with FYRC domains (Rao and Dou 2015). For almost a decade, studies were unable to show enzymatic activity of MLL1 (Rea et al. 2000). However, in 2002 it was shown that a bacterially expressed SET domain of MLL1 has histone $\mathrm{H} 3$ lysine 4 (H3K4) methyltransferase activity on peptides resembling histone tails and recombinant nucleosomes and this catalytic activity was increased if substrates were preacetylated on nearby lysine residues (Milne et al. 2002; Nakamura et al. 2002; Zhang et al. 2015). Later, it was established that the SET domain of MLL1 can catalyze monomethyl and dimethyl and to lesser extent the trimethyl modification of H3K4 (Wu et al. 2013). These studies showed enzymatic activity of the SET domain, but we now know that the full MLL1 complex is required to support efficient modification of
H3K4 (Rao and Dou 2015). Genome-scale occupancy studies using chromatin immunoprecipitation followed by sequencing (ChIP-seq) revealed association of MLL1 with a subset of active promoters (Milne et al. 2005; Wang et al. 2009) as well as certain enhancers (Wang et al. 2011; Yang et al. 2014). Although the exact mechanisms that control the appropriate association of MLL1 with chromatin are still not completely understood, it is plausible to suggest that MLL1 interacts with DNA and chromatin through multiple protein domains with aminoterminal regions such as the CXXC domain interacting with DNA, which is further supported through binding of four PHDs and possibly the bromodomain to modified histone tails (reviewed in Rao and Dou 2015).

Intriguingly, the catalytic activity of MLL1 does not seem to be essential for cell survival or function, as compared with the MLL1 protein itself. Insertion of a stop codon after either exon 3 or 12 leading to loss of MLL1 results in early embryonic death and severe hematopoietic abnormalities (Yu et al. 1995; Yagi et al. 1998). Surprisingly, mice with genetic deletion of only the MLL1 SET domain are born fertile and only show modest skeletal abnormalities and no gross hematopoietic defects (Terranova et al. 2006; Mishra et al. 2014). Moreover, loss of MLL1 does not result in global changes of $\mathrm{H} 3 \mathrm{~K} 4$ methylation, suggesting MLL1 is not the major H3K4 methyltransferase in most cells (Wang et al. 2009). These data prompt questions as to the specific function of $\mathrm{H} 3 \mathrm{~K} 4$ methylation during development. Given the pattern of $\mathrm{H} 3 \mathrm{~K} 4$ methylation throughout the genome and multiple studies showing that perturbation of $\mathrm{H} 3 \mathrm{~K} 4$ methylation leads to relevant changes in gene expression, there is little doubt that $\mathrm{H} 3 \mathrm{~K} 4$ methylation is playing a role in the control of gene expression, but its exact mechanistic contribution remains an open question.

\section{MLL1/KMT2A SUPER COMPLEXES}

The primary structure of MLL1 suggests multiple protein-DNA and protein-protein interactions, many of which have been validated. Indeed, the KMT2 family of proteins form large 
MLL Fusions and Chromatin in Leukemia
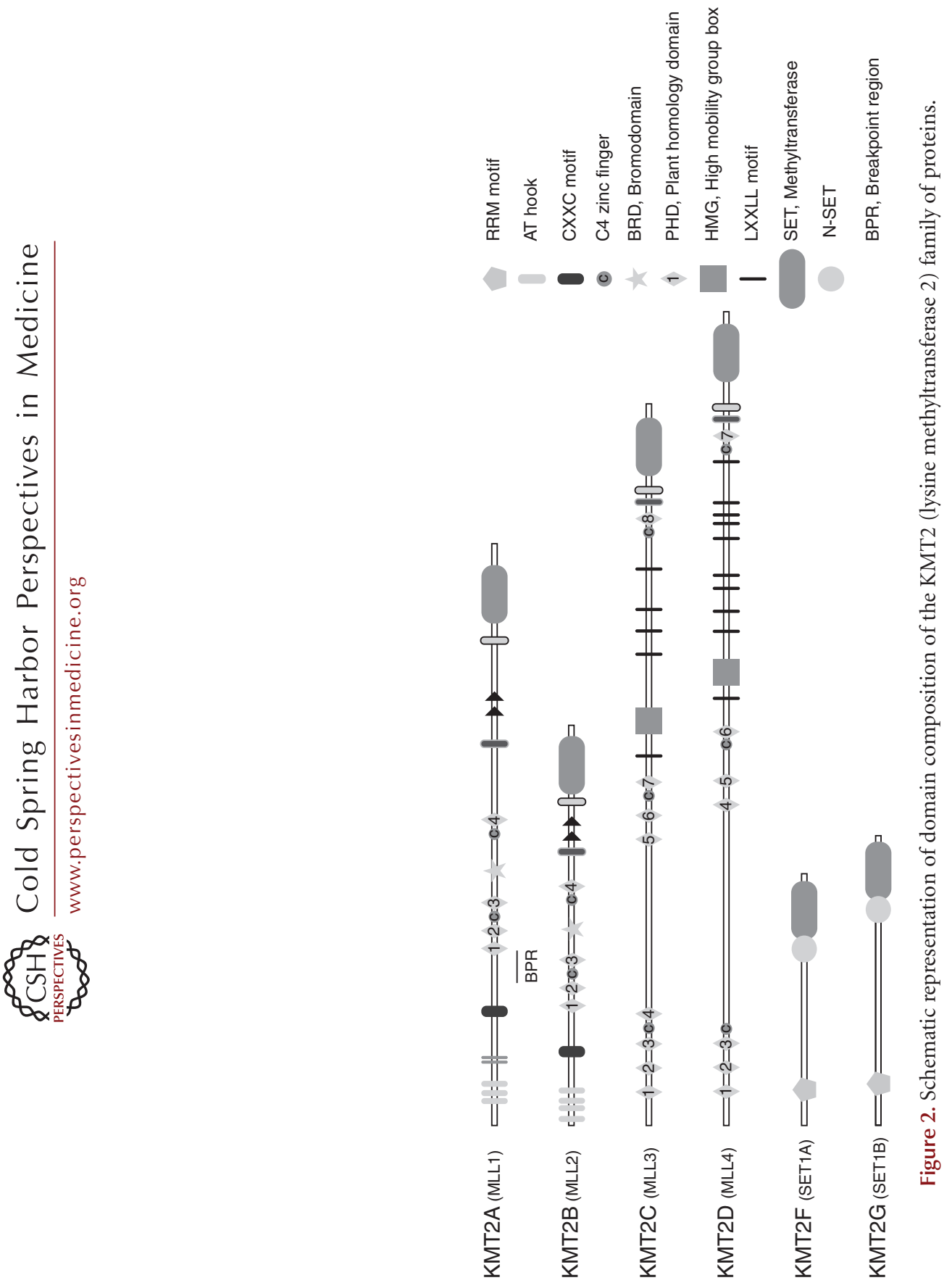
A.V. Krivtsov et al.

multiprotein complexes with common and subgroup specific proteins. For instance, the retinoblastoma binding protein 5 (RbBP5), ASH2 like histone lysine methyltransferase complex subunit (ASH2L), WD repeat 5 (WDR5), and DPY30 are found in complexes with all KMT2 family proteins and are in some cases required for full catalytic activation. Biochemical reconstitution assays show that WDR5, ASH2L, and RbBP5 form a stable core that interacts with MLL1 and potently activate the SET domain catalytic activity (Dou et al. 2006; Patel et al. 2009). At the same time, association of MLL1 with DPY30 only slightly activates SET activity (Patel et al. 2009). Blockage of association of MLL1 with WDR5 using WDR5 interacting (WIN) peptides leads to disintegration of the MLL1 complex in vitro likely leading to the reduction in SET domain catalytic activity (Karatas et al. 2010). In addition to the proteins that are found in all KMT2 protein complexes, there are also subgroup specific subunits. For instance, multiple endocrine neoplasia type 1 (menin or MEN1) (Hughes et al. 2004) and lens epithelium-derived growth factor (LEDGF) (Yokoyama and Cleary 2008) are unique subunits that are found only in the MLL1 and MLL2/KMT2B complexes. Both MEN1 and LEDGF are believed to be necessary for MLL1 and MLL-fusion protein recruitment to target genes. KMT2A can also physically associate with other enzymes that modify chromatin. For instance, MLL1 has been reported to be associated with the histone $\mathrm{H} 3 \mathrm{~K} 9 / \mathrm{H} 4 \mathrm{~K} 16$ acetyltransferase MOF, possibly through WDR5 (Dou et al. 2005). It was observed that active promoters are decorated with H4K16 acetyl modifications in addition to H3K4me3 (Wang et al. 2008). However, another group argues that both MLL1 and MOF associate with WDR5 independently, and are present in different complexes (Dias et al. 2014). Additionally, in specific cellular contexts KMT2A/B were reported to interact with transcription factors such as OCT4 (Ang et al. 2011), E2F (Tyagi et al. 2007), PAX7 (Kawabe et al. 2012), and NF-Y (Fossati et al. 2011); however, the functional meaning of these interactions remains to be studied. Furthermore, it may be the case that MLL1 methylates these transcription factors to modulate their activity as the full complement of MLL1 substrates has not been defined. This bouquet of MLL1 interactions with other proteins opens the possibility that the various complexes may play different roles in the control of gene expression.

\section{MECHANISMS OF MLL-FUSION ACTION}

At least two potentially complementary mechanisms for MLL-fusion function have been identified and studied. The first includes recruitment of the super elongation complex (SEC) by MLL-fusion proteins. ELL, one of the more frequent MLL fusion partners (Thirman et al. 1994), was shown to be required for elongation by RNA Pol II (Shinobu et al. 1999). This finding initiated the concept that MLL fusions may function to activate transcription of target genes via directly influencing transcriptional elongation by RNA Pol II. Subsequent characterization of the proteins encoded by the most frequent fusion partner genes AF4, $\mathrm{AF}$, and ENL were found to be members of a large multiprotein complex that has been isolated and given multiple names including the elongation-assisting multiprotein complex (EAP) and the SEC (Mueller et al. 2007; Lin et al. 2010). These complexes include at least ENL or AF9, AF4, AF5 (all known MLL-fusion partners) and members of the transcriptional elongation complex b (pTEFb). $\mathrm{P}-\mathrm{TEFb}$ is a heterodimer of CDK9 and CyclinT1 or T2 that phosphorylates serine 2 within the carboxy-terminal repeat domain of RNA polymerase II which releases RNA Pol II from the paused state (Jonkers and Lis 2015). The polymerase-associated factor elongation complex (PAF1C) can also be coimmunoprecipitated (co-IP) with MLL1 as well as MLL-ENL (Mueller et al. 2007). PAF1C is associated with elongating RNA polymerase II and can influence proper methylation of H3K4 (Wood et al. 2003). It appears that PAF1 complex may serve as a dock for interaction of elongating RNA Pol II and other histone chromatin remodeling complexes (Wang et al. 2008). Moreover, PAF1 appears to be involved in regulation of methylation on $\mathrm{H} 3 \mathrm{~K} 4$ and $\mathrm{H} 3 \mathrm{~K} 79$ residues through recruitment 
of E2/E3 ubiquitin ligase complex (Wood et al. 2003). Therefore, MLL fusions may act to bring together two independently regulated complexes, MLL1 and SEC, into a single and potentially unregulated complex that allows unrestricted transcription of genes directly bound by the MLL-fusion proteins.

The second potential mechanism stems from the seminal identification of the interaction between one of the common MLL fusion partners, AF10, with the histone H3 lysine 79 (H3K79) methyltransferase DOT1L (Okada et al. 2005). Cells transformed with MLL-AF10 were shown to have elevated levels of H3K79 methylation associated with the MLL-fusion target gene HoxA9 gene in vitro. Coincidentally, SEC complex members AF9 and ENL (both MLL fusion partners) can bind DOT1L directly in addition to the SEC (Erfurth et al. 2004; Zhang et al. 2006; Bitoun et al. 2007; Kuntimaddi et al. 2015). However, the regions of the ENL and AF9 proteins that interact with DOT1L and SEC are overlapping and therefore it appears that the SEC complex and DOT1L complex are two independent complexes (Shen et al. 2013). Given that H3K79me2 is also broadly correlated with actively transcribed genes, it is attractive to hypothesize that the MLL fusions recruit DOT1L to target genes to enhance H3K79 methylation and therefore positively regulate expression MLL-fusion target genes (Krivtsov and Armstrong 2007). This hypothesis was confirmed by the finding that mouse and human B-ALLs expressing an MLL-AF4 fusion protein have significantly increased H3K79 di-methylation on MLL-AF4bound genes (Guenther et al. 2008; Krivtsov et al. 2008). Furthermore, elevated H3K79 methylation has been found at regions of chromatin bound by MLL-fusion proteins in all MLL-fusion leukemia models that have been assessed including fusions such as MLL-AF6 that do not appear to interact with either DOT1L or SEC (Yun et al. 2011; Deshpande et al. 2013). Therefore, it may be that elevated H3K79 methylation across MLL-fusion target genes is common feature among all $M L L$-rearranged acute leukemias. However, mice transgenic for an Mll-LacZ fusion also develop AML with similar latency as mice transgenic for Mll-AF9 (Dobson et al 2000.). This has been hypothesized to be a result of oligomerization of the amino terminus of Mll. Therefore, it may be that both the DOT1L complexes and SECs are aberrantly targeted to MLL-fusion target genes in many cases, but this is unlikely to completely account for transformation. Furthermore, DOT1L is a physiologic regulator of Hox gene expression during normal hematopoietic development. Thus, the details defining how the SEC and DOT1L complexes influence leukemic gene expression remain a work in progress.

Perhaps, other mechanisms exist to recruit or influence DOT1L and/or SEC at MLL-fusion target genes. Leukemias with an MLL-PTD retain a SET domain. MLL-PTDs have not been reported to interact with proteins outside the normal MLL1 complexes. It is interesting to note the only difference between the MLL-PTD and MLL1 proteins is duplication of the AThook and CXXC domains. Therefore, it is not immediately clear how this would influence either the SEC or DOT1L complexes. ChIP-seq experiments have, however, detected extensive H3K79me2 hyper methylation of several genes in cells expressing an MLL-PTD, and these leukemia cells are quite sensitive to DOT1L inhibition, again suggesting a role for DOT1L in this form of MLL1/KMT2A leukemia (Kühn et al. 2015).

The exquisite sensitivity of leukemias with MLL1/KMT2A rearrangements to DOT1L inhibition has prompted the question as to the function of DOT1L and H3K79 methylation. H3K79 methylation is somewhat unique compared with many histone modifications and therefore may also function differently. Lysine 79 on histone 3 is found in the globular region of $\mathrm{H} 3$ as opposed to other amino acid residues that are targets of modifications, which most often reside in histone tails. There are currently no known proteins or domains that can interact with methylated H3K79. This is also different from the more highly studied lysine 4 and lysine 27 residues that, when methylated, are "read" by specific protein domains (Yun et al. 2011; Vlaming and van Leeuwen 2016). There is also no known demethylase that removes 
A.V. Krivtsov et al.

monomethylation, dimethylation, or trimethylation from H3K79. All of these characteristics suggest that $\mathrm{H} 3 \mathrm{~K} 79$ may play a unique role in cellular biology. Consistent with the lack of a demethylase, when DOT1L is inhibited, the kinetics of $\mathrm{H} 3 \mathrm{~K} 79 \mathrm{me} 2 / 3$ loss is relatively slow and more consistent with dilution during cell division rather than active removal by a demethylase (Bernt et al. 2011). At the same time, H3K79me2 is present on most genes with high-level expression (Steger et al. 2008). Recently, a mechanism describing how H3K79 methylation may influence transcription was discovered in a genome-scale shRNA "rescue" screen. It appears that H3K79 methylation in leukemia cells prevents association of the NAD-dependent deacetylase sirtuin-1 (SIRT1) complex. Upon inhibition of DOT1L, SIRT1 localizes to regions of chromatin that were previously modified with $\mathrm{H} 3 \mathrm{~K} 79$ methylation. This leads to loss of $\mathrm{H} 3 \mathrm{~K} 9$ and $\mathrm{H} 4 \mathrm{~K} 16$ acetylation and subsequent histone $\mathrm{H} 3$ lysine 9 methylation (H3K9me3) via the SUV39 enzymes. This leads to suppression of gene transcription (Chen et al. 2015). Therefore, H3K79 methylation may prevent repressive mechanisms from converting chromatin from a state that allows gene expression to a state that does not allow access of the transcriptional machinery. This is consistent with pioneering work in budding yeast in which it has been shown that H3K79 methylation inhibits Sir protein spreading on chromatin (Sneppen and Dodd 2015).

\section{POTENTIAL THERAPEUTIC STRATEGIES THAT TARGET CHROMATIN IN MLL-FUSION LEUKEMIA}

Traditionally, patients with $M L L$ rearrangements are assigned to intermediate- or poorrisk groups with long-term-survival rates at or below $50 \%$. This group of patients would greatly benefit from development of novel therapeutic approaches. Because MLL fusions seem to act in concert with a number of other enzymes, those may potentially represent therapeutic targets. Recent efforts have made great progress toward identification of small molecule inhibitors that target MLL-fusion-associated mechanisms as well as other pathways the suppression of which might lead to synthetic lethality with the MLLfusion protein.

Aberrant recruitment of the DOT1L enzyme by MLL fusions provided a rationale for development and testing of small molecule inhibitors. DOT1L inhibitors efficiently and specifically eradicated leukemia cells in vitro and in vivo model systems (Daigle et al. 2011, 2013). Phase 1 clinical studies assessing a small molecule DOT1L inhibitor in adults and children with relapsed or refractory leukemias have been completed. Approximately 20\% of patients showed some type of clinical or biological response, two of which went into remission. Of importance, no side effects of the inhibitor, EPZ-5676, have been reported despite initial concerns of potential transcriptional suppression of the $2-5 \times 10^{3}$ genes that are normally marked by H3K79me2 (Stein and Tallman 2016). The initial successful development of DOT1L inhibitors was followed by small molecule discovery by other groups and there are currently multiple DOT1L inhibitors with varying pharmacokinetic properties available for research (Yu et al. 2012; Yi et al. 2015; Chen et al. 2016; Dafflon et al. 2016; Spurr et al. 2016). Although these initial results are encouraging, there is no doubt these approaches will need to be combined with other therapies to realize the maximal therapeutic benefit. Further development of DOT1L inhibitors will proceed with combination approaches as they are identified.

A second interesting potential therapeutic approach is disruption of the MLL-fusion complex via inhibition of the interaction of the amino terminus of MLL with the MLL-fusion complex member menin 1 (MEN). MLL-fusion-driven gene expression and leukemia cell proliferation is dependent on interaction with MEN (Yokoyama and Cleary 2008). Several small molecules that disrupt interaction of menin with MLL fusions have been identified (Grembecka et al. 2012; Borkin et al. 2015; Xu et al. 2016). Treatment of leukemia cells expressing various fusion such as MLL-ENL, MLLAF9, MLL-CBP, MLL-AF6, MLL-GAS7, and MLL-AF1P with MI-2-2 or MI-503 at nanomolar concentrations results in strong growth inhi- 
bition and MI-503 has antileukemia activity in vivo. Menin-MLL fusion interaction inhibition shows some degree of selectivity as cells expressing either Hoxa9-Meis1 or E2A-HLF oncogenes are not sensitive to the same concentrations of MI-2-2 in vitro. Moreover, disruption of MLL/ MEN1 interaction results in rapid differentiation of the cells in vitro as assessed by morphology. Of potential therapeutic importance, combined inhibition of the MLL fusionMEN1 interaction and DOT1L activity enhances leukemia cell differentiation ( $\mathrm{He}$ et al. 2016). The advantage of this approach is relative specificity because menin 1 interacts only with MLL fusion, MLL1, and MLL2/KMT2B and does not affect other members of the KMT2 family. Other approaches to disrupt the MLL-fusion complex have also been developed. One potentially interesting approach in inhibition of the interaction between WDR5 and MLL1, which leads to profound biochemical changes in the complexes similar to loss of wild-type $M l l$ in mice, including global gene expression changes. Tool molecules, including the WDR5/MLL1 inhibitor MM-401, induced growth arrest followed by differentiation of AML cells expressing MLL fusions (Cao et al. 2014). Although these initial data are of interest, these molecules are not particularly potent so the full potential of this approach awaits development of better small-molecule inhibitors. Whether or not WDR5 inhibition will show selectivity toward MLL-fusion leukemias remains to be fully addressed and is a concern because WDR5 is found in all KMT2 complexes and thus could have profound cellular effects. Based on this progress, the development of inhibitors of these protein-protein interactions remains an active area of investigation.

Another potential approach that has garnered much interest is inhibition of the BET bromodomains. BRD4, a member of BET family of proteins, was also discovered as an interesting cancer dependency in $M L L$-rearranged AML using genome-wide shRNA screening (Dawson et al. 2011; Zuber et al. 2011). BRD4 is a "chromatin reader" protein that binds acetylated lysines in the $\mathrm{H} 3$ and $\mathrm{H} 4$ tails through its acetyllysine binding bromodomain. BRD4 is found associated with many active enhancers throughout the genome, but particular excitement has focused on enhancers with unusually high levels of H3K27 acetylation and BRD4 binding. The enhancers, termed super-enhancers, may be particularly important as removal of BRD4 from super-enhancers like the $c-M y c$ enhancer leads to rapid down-regulation of $M y c$ gene expression. Genetic and shRNA-mediated silencing of BRD4 expression also resulted in differentiation of MLL-AF9 expressing leukemia cells and suppression of leukemogenesis in vitro and in vivo. However, the antiproliferative effects of the bromodomain inhibitors were broadly observed in other genetically defined types of AML as well as in other cancers (Delmore et al. 2011). Therefore, it is likely that bromodomain inhibitors are targeting a myeloid lineage program rather than the MLL-fusion driven program per se. Clinical trials with bromodomain inhibitors are ongoing and we should get an assessment of their potential clinical activity in the near future.

Another recent chromatin-targeted approach came from more focused studies on small molecules that inhibit the mediator component cyclin-dependent kinase 8 (CDK8). MLL-fusion-expressing cell lines are particularly sensitive to CDK8 inhibition. CDK8 is colocalized with MED1, BRD4, and H3K27Ac on super-enhancers providing a potential explanation for this sensitivity. However, inhibition of CDK8 enzymatic activity resulted in disproportionate activation of transcription of genes associated with super-enhancers, which is the inverse of the effects of BET inhibitors. The overexpression of such super-enhancer-associated tumor suppressors as IRF1, IRF8, CEBPA, and ETV6 seems to contribute to the antiproliferative effects of CDK8 inhibition. This study suggests that viability of leukemia cells might depend on a precise "dosage" of super-enhancer-associated gene expression to maintain proliferation and the undifferentiated state (Pelish et al. 2015). These studies suggest that either suppression of a gene expression program that inhibits differentiation or enhancement of a gene expression program that drives differentiation might be therapeutic approaches in 
A.V. Krivtsov et al.

AML. Further studies will help clarify this possibility.

\section{CONCLUSIONS}

It is now clear that disruption of the normal cellular processes that control chromatin state is common in human cancers. The best studied of the mutations in chromatin regulators is the MLL fusion that drives expression of developmental gene expression in cells that should not express these programs. Studies have now shown that this "aberrant" gene expression can be reversed by inhibition of chromatin-based mechanism leading to the hope that this will allow new therapeutic development. We are still in the early days of assessment of such approaches, but the initial clinical trials suggest these approaches do have clinical activity. Studying acute leukemias bearing $M L L$ rearrangements has provided valuable insight into the mechanisms of this disease as well as led the way for development of small molecule inhibitors targeting epigenetic mechanisms. However, it is also clear that much work needs to be performed to fully understand chromatin biology such that we can use these new approaches for the greatest benefit in patients with cancer.

\section{ACKNOWLEDGMENTS}

This work was supported by National Institutes of Health (NIH) Grants PO1 CA66996, R01 CA140575, the Leukemia \& Lymphoma society, and Gabrielle's Angel Research Foundation (to S.A.A.). S.A.A. is a consultant for Epizyme Inc., Vitae Inc., and Imago Biosciences.

\section{REFERENCES}

Ang YS, Tsai SY, Lee DF, Monk J, Su J, Ratnakumar K, Ding J, Ge Y, Darr H, Chang B, et al. 2011. Wdr5 mediates selfrenewal and reprogramming via the embryonic stem cell core transcriptional network. Cell 145: 183-197.

Bernt KM, Zhu N, Sinha AU, Vempati S, Faber J, Krivtsov AV, Feng Z, Punt N, Daigle A, Bullinger L, et al. 2011. MLLrearranged leukemia is dependent on aberrant H3K79 methylation by DOT1L. Cancer Cell 20: 66-78.

Bitoun E, Oliver PL, Davies KE. 2007. The mixed-lineage leukemia fusion partner AF4 stimulates RNA polymerase
II transcriptional elongation and mediates coordinated chromatin remodeling. Hum Mol Genet 16: 92-106.

Borkin D, He S, Miao H, Kempinska K, Pollock J, Chase J, Purohit T, Malik B, Zhao T, Wang J, et al. 2015. Pharmacologic inhibition of the menin-MLL interaction blocks progression of MLL leukemia in vivo. Cancer Cell 27: 589-602.

Cao F, Townsend EC, Karatas H, Xu J, Li L, Lee S, Liu L, Chen Y, Ouillette P, Zhu J, et al. 2014. Targeting MLL1 H3K4 methyltransferase activity in mixed-lineage leukemia. Mol Cell 53: 247-261.

Chaplin T, Bernard O, Beverloo HB, Saha V, Hagemeijer A, Berger R, Young BD. 1995. The $t(10 ; 11)$ translocation in acute myeloid leukemia (M5) consistently fuses the leucine zipper motif of AF10 onto the HRX gene. Blood 86: 2073-2076.

Chen CW, Koche RP, Sinha AU, Deshpande AJ, Zhu N, Eng R, Doench JG, Xu H, Chu SH, Qi J, et al. 2015. DOT1L inhibits SIRT1-mediated epigenetic silencing to maintain leukemic gene expression in $M L L$-rearranged leukemia. Nat Med 21: 335-343.

Chen C, Zhu H, Stauffer F, Caravatti G, Vollmer S, Machauer R, Holzer P, Möbitz H, Scheufler C, Klumpp M, et al. 2016. Discovery of novel Dot1L inhibitors through a structure-based fragmentation approach. ACS Med Chem Lett 7: 735-740.

Collins EC, Pannell R, Simpson EM, Forster A, Rabbitts TH. 2000. Inter-chromosomal recombination of Mll and Af9 genes mediated by cre-loxP in mouse development. EMBO Rep 1: 127-132.

Corral J, Lavenir I, Impey H, Warren AJ, Forster A, Larson TA, Bell S, McKenzie AN, King G, Rabbitts TH. 1996. An Mll-AF9 fusion gene made by homologous recombination causes acute leukemia in chimeric mice: A method to create fusion oncogenes. Cell 85: 853-861.

Cozzio A, Passegué E, Ayton PM, Karsunky H, Cleary ML, Weissman IL. 2003. Similar MLL-associated leukemias arising from self-renewing stem cells and short-lived myeloid progenitors. Genes Dev 17: 3029-3035.

Dafflon C, Craig VJ, Méreau H, Gräsel J, Schacher Engstler B, Hoffman G, Nigsch F, Gaulis S, Barys L, Ito M, et al. 2016. Complementary activities of DOT1L and menin inhibitors in MLL-rearranged leukemia. Leukemia. doi: 10.1038/leu.2016.327.

Daigle SR, Olhava EJ, Therkelsen CA, Majer CR, Sneeringer CJ, Song J, Johnston LD, Scott MP, Smith JJ, Xiao Y, et al. 2011. Selective killing of mixed lineage leukemia cells by a potent small-molecule DOT1L inhibitor. Cancer Cell 20: 53-65.

Daigle SR, Olhava EJ, Therkelsen CA, Basavapathruni A, Jin L, Boriack-Sjodin PA, Allain CJ, Klaus CR, Raimondi A, Scott MP, et al. 2013. Potent inhibition of DOT1L as treatment of MLL-fusion leukemia. Blood 122: 10171025.

Dawson MA, Prinjha RK, Dittmann A, Giotopoulos G, Bantscheff M, Chan WI, Robson SC, Chung CW, Hopf C, Savitski MM, et al. 2011. Inhibition of BET recruitment to chromatin as an effective treatment for MLLfusion leukaemia. Nature 478: 529-533.

Delmore JE, Issa GC, Lemieux ME, Rahl PB, Shi J, Jacobs HM, Kastritis E, Gilpatrick T, Paranal RM, Qi J, et al. 
2011. BET bromodomain inhibition as a therapeutic strategy to target c-Myc. Cell 146: 904-917.

Deshpande AJ, Chen L, Fazio M, Sinha AU, Bernt KM, Banka D, Dias S, Chang J, Olhava EJ, Daigle SR, et al. 2013. Leukemic transformation by the MLL-AF6 fusion oncogene requires the H3K79 methyltransferase Dot1l. Blood 121: 2533-2541.

Dias J, Van Nguyen N, Georgiev P, Gaub A, Brettschneider J, Cusack S, Kadlec J, Akhtar A. 2014. Structural analysis of the KANSL1/WDR5/KANSL2 complex reveals that WDR5 is required for efficient assembly and chromatin targeting of the NSL complex. Genes Dev 28: 929-942.

Dick JE. 2005. Acute myeloid leukemia stem cells. Ann NY Acad Sci 1044: 1-5.

Dobson CL, Warren AJ, Pannell R, Forster A, Rabbitts TH. 2000. Tumorigenesis in mice with a fusion of the leukaemia oncogene $M l l$ and the bacterial lacZ gene. $E M B O J$ 19: $843-851$.

Domer PH, Fakharzadeh SS, Chen CS, Jockel J, Johansen L, Silverman GA, Kersey JH, Korsmeyer SJ. 1993. Acute mixed-lineage leukemia $\mathrm{t}(4 ; 11)(\mathrm{q} 21 ; \mathrm{q} 23)$ generates an MLL-AF4 fusion product. Proc Natl Acad Sci 90: 7884-7888.

Dou Y, Milne TA, Tackett AJ, Smith ER, Fukuda A, Wysocka J, Allis CD, Chait BT, Hess JL, Roeder RG. 2005. Physical association and coordinate function of the $\mathrm{H} 3 \mathrm{~K} 4$ methyltransferase MLL1 and the H4 K16 acetyltransferase MOF. Cell 121: 873-885.

Dou Y, Milne TA, Ruthenburg AJ, Lee S, Lee JW, Verdine GL, Allis CD, Roeder RG. 2006. Regulation of MLL1 H3K4 methyltransferase activity by its core components. Nat Struct Mol Biol 13: 713-719.

Erfurth F, Hemenway CS, de Erkenez AC, Domer PH. 2004. MLL fusion partners AF4 and AF9 interact at subnuclear foci. Leukemia 18: 92-102.

Forster A, Pannell R, Drynan LF, McCormack M, Collins EC, Daser A, Rabbitts TH. 2003. Engineering de novo reciprocal chromosomal translocations associated with $\mathrm{Mll}$ to replicate primary events of human cancer. Cancer Cell 3: 449-458.

Fossati A, Dolfini D, Donati G, Mantovani R. 2011. NF-Y recruits Ash2L to impart $\mathrm{H} 3 \mathrm{~K} 4$ trimethylation on CCAAT promoters. PLOS ONE 6: e17220.

Grembecka J, He S, Shi A, Purohit T, Muntean AG, Sorenson RJ, Showalter HD, Murai MJ, Belcher AM, Hartley T, et al. 2012. Menin-MLL inhibitors reverse oncogenic activity of MLL fusion proteins in leukemia. Nat Chem Biol 8: 277-284.

Gu Y, Nakamura T, Alder H, Prasad R, Canaani O, Cimino G, Croce CM, Canaani E. 1993. The t $(4 ; 11)$ chromosome translocation of human acute leukemias fuses the $A L L-1$ gene, related to Drosophila trithorax, to the $A F-4$ gene. Cell 71: 701-708.

Guenther MG, Lawton LN, Rozovskaia T, Frampton GM, Levine SS, Volkert TL, Croce CM, Nakamura T, Canaani E, Young RA. 2008. Aberrant chromatin at genes encoding stem cell regulators in human mixed-lineage leukemia. Genes Dev 22: 3403-3408.

He S, Malik B, Borkin D, Miao H, Shukla S, Kempinska K, Purohit T, Wang J, Chen L, Parkin B, et al. 2016. MeninMLL inhibitors block oncogenic transformation by MLL- fusion proteins in a fusion partner-independent manner. Leukemia 30: 508-513.

Hughes CM, Rozenblatt-Rosen O, Milne TA, Copeland TD, Levine SS, Lee JC, Hayes DN, Shanmugam KS, Bhattacharjee A, Biondi CA, et al. 2004. Menin associates with a trithorax family histone methyltransferase complex and with the Hoxc8 locus. Mol Cell 13: 587-597.

Jonkers I, Lis JT. 2015. Getting up to speed with transcription elongation by RNA polymerase II. Nat Rev Mol Cell Biol 16: 167-177.

Karatas H, Townsend EC, Bernard D, Dou Y, Wang S. 2010. Analysis of the binding of mixed lineage leukemia 1 (MLL1) and histone 3 peptides to WD repeat domain 5 (WDR5) for the design of inhibitors of the MLL1WDR5 interaction. J Med Chem 53: 5179-5185.

Kawabe Y, Wang YX, McKinnell IW, Bedford MT, Rudnicki MA. 2012. Carm1 regulates Pax7 transcriptional activity through MLL1/2 recruitment during asymmetric satellite stem cell divisions. Cell Stem Cell 11: 333-345.

Krivtsov AV, Armstrong SA. 2007. MLL translocations, histone modifications and leukaemia stem-cell development. Nat Rev Cancer 7: 823-833.

Krivtsov AV, Twomey D, Feng Z, Stubbs MC, Wang Y, Faber J, Levine JE, Wang J, Hahn WC, Gilliland DG, et al. 2006. Transformation from committed progenitor to leukaemia stem cell initiated by MLL-AF9. Nature 442: 818822.

Krivtsov AV, Feng Z, Lemieux ME, Faber J, Vempati S, Sinha AU, Xia X, Jesneck J, Bracken AP, Silverman LB, et al. 2008. H3K79 methylation profiles define murine and human MLL-AF4 leukemias. Cancer Cell 14: 355-368.

Kühn MW, Hadler MJ, Daigle SR, Koche RP, Krivtsov AV, Olhava EJ, Caligiuri MA, Huang G, Bradner JE, Pollock RM, et al. 2015. MLL partial tandem duplication leukemia cells are sensitive to small molecule DOT1L inhibition. Haematologica 100: e190-193.

Kuntimaddi A, Achille NJ, Thorpe J, Lokken AA, Singh R, Hemenway CS, Adli M, Zeleznik-Le NJ, Bushweller JH. 2015. Degree of recruitment of DOT1L to MLL-AF9 defines level of H3K79 di- and tri-methylation on target genes and transformation potential. Cell Rep 11: 808820.

Lin C, Smith ER, Takahashi H, Lai KC, Martin-Brown S, Florens L, Washburn MP, Conaway JW, Conaway RC, Shilatifard A. 2010. AFF4, a component of the ELL/P$\mathrm{TEFb}$ elongation complex and a shared subunit of MLL chimeras, can link transcription elongation to leukemia. Mol Cell 37: 429-437.

Meyer C, Hofmann J, Burmeister T, Gröger D, Park TS, Emerenciano M, Pombo de Oliveira M, Renneville A, Villarese P, Macintyre E, et al. 2013. The MLL recombinome of acute leukemias in 2013. Leukemia 27: 21652176.

Milne TA, Briggs SD, Brock HW, Martin ME, Gibbs D, Allis CD, Hess JL. 2002. MLL targets SET domain methyltransferase activity to Hox gene promoters. Mol Cell 10: 1107-1117.

Milne TA, Dou Y, Martin ME, Brock HW, Roeder RG, Hess JL. 2005. MLL associates specifically with a subset of transcriptionally active target genes. Proc Natl Acad Sci 102: $14765-14770$. 
A.V. Krivtsov et al.

Mishra BP, Zaffuto KM, Artinger EL, Org T, Mikkola HK, Cheng C, Djabali M, Ernst P. 2014. The histone methyltransferase activity of MLL1 is dispensable for hematopoiesis and leukemogenesis. Cell Rep 7: 1239-1247.

Mueller D, Bach C, Zeisig D, Garcia-Cuellar MP, Monroe S, Sreekumar A, Zhou R, Nesvizhskii A, Chinnaiyan A, Hess $\mathrm{JL}$, et al. 2007. A role for the MLL fusion partner ENL in transcriptional elongation and chromatin modification. Blood 110: 4445-4454.

Muntean AG, Giannola D, Udager AM, Hess JL. 2008. The PHD fingers of MLL block MLL fusion protein-mediated transformation. Blood 112: 4690-4693.

Nakamura T, Mori T, Tada S, Krajewski W, Rozovskaia T, Wassell R, Dubois G, Mazo A, Croce CM, Canaani E. 2002. ALL-1 is a histone methyltransferase that assembles a supercomplex of proteins involved in transcriptional regulation. Mol Cell 10: 1119-1128.

Okada Y, Feng Q, Lin Y, Jiang Q, Li Y, Coffield VM, Su L, Xu G, Zhang Y. 2005. hDOT1L links histone methylation to leukemogenesis. Cell 121: 167-178.

Patel A, Dharmarajan V, Vought VE, Cosgrove MS. 2009. On the mechanism of multiple lysine methylation by the human mixed lineage leukemia protein-1 (MLL1) core complex. J Biol Chem 284: 24242-24256.

Pelish HE, Liau BB, Nitulescu II, Tangpeerachaikul A, Poss ZC, Da Silva DH, Caruso BT, Arefolov A, Fadeyi O, Christie AL, et al. 2015. Mediator kinase inhibition further activates super-enhancer-associated genes in AML. Nature 526: 273-276.

Prasad R, Leshkowitz D, Gu Y, Alder H, Nakamura T, Saito H, Huebner K, Berger R, Croce CM, Canaani E. 1994 Leucine-zipper dimerization motif encoded by the AF17 gene fused to ALL-1 (MLL) in acute leukemia. Proc Natl Acad Sci 91: 8107-8111.

Rao RC, Dou Y. 2015. Hijacked in cancer: The KMT2 (MLL) family of methyltransferases. Nat Rev Cancer 15: 334346.

Rea S, Eisenhaber F, O'Carroll D, Strahl BD, Sun ZW, Schmid M, Opravil S, Mechtler K, Ponting CP, Allis CD, et al. 2000. Regulation of chromatin structure by site-specific histone H3 methyltransferases. Nature 406: 593-599.

Rowley JD. 1993. Rearrangements involving chromosome band 11Q23 in acute leukaemia. Semin Cancer Biol 4: 377-385.

Schichman SA, Caligiuri MA, Gu Y, Strout MP, Canaani E, Bloomfield CD, Croce CM. 1994. ALL-1 partial duplication in acute leukemia. Proc Natl Acad Sci 91: 6236-6239.

Shen C, Jo SY, Liao C, Hess JL, Nikolovska-Coleska Z. 2013. Targeting recruitment of disruptor of telomeric silencing 1-like (DOT1L): Characterizing the interactions between DOT1L and mixed lineage leukemia (MLL) fusion proteins. J Biol Chem 288: 30585-30596.

Shinobu N, Maeda T, Aso T, Ito T, Kondo T, Koike K, Hatakeyama M. 1999. Physical interaction and functional antagonism between the RNA polymerase II elongation factor ELL and p53. J Biol Chem 274: 17003-17010.

Sneppen K, Dodd IB. 2015. Cooperative stabilization of the SIR complex provides robust epigenetic memory in a model of SIR silencing in Saccharomyces cerevisiae. Epigenetics 10: 293-302.
Somervaille TC, Cleary ML. 2006. Identification and characterization of leukemia stem cells in murine MLL-AF9 acute myeloid leukemia. Cancer Cell 10: 257-268.

Spurr SS, Bayle ED, Yu W, Li F, Tempel W, Vedadi M, Schapira M, Fish PV. 2016. New small molecule inhibitors of histone methyl transferase DOT1L with a nitrile as a nontraditional replacement for heavy halogen atoms. Bioorg Med Chem Lett 26: 4518-4522.

Steger DJ, Lefterova MI, Ying L, Stonestrom AJ, Schupp M, Zhuo D, Vakoc AL, Kim JE, Chen J, Lazar MA, et al. 2008. DOT1L/KMT4 recruitment and H3K79 methylation are ubiquitously coupled with gene transcription in mammalian cells. Mol Cell Biol 28: 2825-2839.

Stein EM, Tallman MS. 2016. Emerging therapeutic drugs for AML. Blood 127: 71-78.

Strissel PL, Strick R, Rowley JD, Zeleznik-Le NJ. 1998. An in vivo topoisomerase II cleavage site and a DNase I hypersensitive site colocalize near exon 9 in the $M L L$ breakpoint cluster region. Blood 92: 3793-3803.

Terranova R, Agherbi H, Boned A, Meresse S, Djabali M. 2006. Histone and DNA methylation defects at Hox genes in mice expressing a SET domain-truncated form of Mll. Proc Natl Acad Sci 103: 6629-6634.

Thirman MJ, Levitan DA, Kobayashi H, Simon MC, Rowley JD. 1994. Cloning of ELL, a gene that fuses to $M L L$ in a $\mathrm{t}(11 ; 19)$ (q23;p13.1) in acute myeloid leukemia. Proc Natl Acad Sci 91: 12110-12114.

Tkachuk DC, Kohler S, Cleary ML. 1992. Involvement of a homolog of Drosophila trithorax by 11q23 chromosomal translocations in acute leukemias. Cell 71: 691-700.

Tyagi S, Chabes AL, Wysocka J, Herr W. 2007. E2F activation of S phase promoters via association with HCF-1 and the MLL family of histone H3K4 methyltransferases. Mol Cell 27: 107-119.

Vlaming H, van Leeuwen F. 2016. The upstreams and downstreams of H3K79 methylation by DOT1L. Chromosoma 125: 593-605.

Wang J, Iwasaki H, Krivtsov A, Febbo PG, Thorner AR, Ernst P, Anastasiadou E, Kutok JL, Kogan SC, Zinkel SS, et al. 2005. Conditional MLL-CBP targets GMP and models therapy-related myeloproliferative disease. EMBO J 24: 368-381.

Wang P, Bowl MR, Bender S, Peng J, Farber L, Chen J, Ali A, Zhang Z, Alberts AS, Thakker RV, et al. 2008. Parafibromin, a component of the human PAF complex, regulates growth factors and is required for embryonic development and survival in adult mice. Mol Cell Biol 28: 2930-2940.

Wang Z, Zang C, Rosenfeld JA, Schones DE, Barski A, Cuddapah S, Cui K, Roh TY, Peng W, Zhang MQ, et al. 2008. Combinatorial patterns of histone acetylations and methylations in the human genome. Nat Genet 40: 897-903.

Wang P, Lin C, Smith ER, Guo H, Sanderson BW, Wu M, Gogol M, Alexander T, Seidel C, Wiedemann LM, et al 2009. Global analysis of H3K4 methylation defines MLL family member targets and points to a role for MLL1mediated $\mathrm{H} 3 \mathrm{~K} 4$ methylation in the regulation of transcriptional initiation by RNA polymerase II. Mol Cell Biol 29: 6074-6085.

Wang KC, Yang YW, Liu B, Sanyal A, Corces-Zimmerman R, Chen Y, Lajoie BR, Protacio A, Flynn RA, Gupta RA, et al. 
MLL Fusions and Chromatin in Leukemia

2011. A long noncoding RNA maintains active chromatin to coordinate homeotic gene expression. Nature 472: $120-124$.

Wood A, Schneider J, Dover J, Johnston M, Shilatifard A. 2003. The Paf1 complex is essential for histone monoubiquitination by the Rad6-Brel complex, which signals for histone methylation by COMPASS and Dotlp. J Biol Chem 278: 34739-34742.

Wu L, Lee SY, Zhou B, Nguyen UT, Muir TW, Tan S, Dou Y. 2013. ASH2L regulates ubiquitylation signaling to MLL: Trans-regulation of H3 K4 methylation in higher eukaryotes. Mol Cell 49: 1108-1120.

Xu Y, Yue L, Wang Y, Xing J, Chen Z, Shi Z, Liu R, Liu YC, Luo X, Jiang H, et al. 2016. Discovery of novel inhibitors targeting the menin-mixed lineage leukemia interface using pharmacophore- and docking-based virtual screening. J Chem Inf Model 56: 1847-1855.

Yagi H, Deguchi K, Aono A, Tani Y, Kishimoto T, Komori T. 1998. Growth disturbance in fetal liver hematopoiesis of Mll-mutant mice. Blood 92: 108-117.

Yang YW, Flynn RA, Chen Y, Qu K, Wan B, Wang KC, Lei M, Chang HY. 2014. Essential role of lncRNA binding for WDR5 maintenance of active chromatin and embryonic stem cell pluripotency. Elife 3: e02046.

Yi JS, Federation AJ, Qi J, Dhe-Paganon S, Hadler M, Xu X St Pierre R, Varca AC, Wu L, Marineau JJ, et al. 2015. Structure-guided DOT1L probe optimization by labelfree ligand displacement. ACS Chem Biol 10: 667-674.
Yokoyama A, Cleary ML. 2008. Menin critically links MLL proteins with LEDGF on cancer-associated target genes. Cancer Cell 14: 36-46.

Yu BD, Hess JL, Horning SE, Brown GA, Korsmeyer SJ. 1995. Altered Hox expression and segmental identity in Mllmutant mice. Nature 378: 505-508.

Yu W, Chory EJ, Wernimont AK, Tempel W, Scopton A, Federation A, Marineau JJ, Qi J, Barsyte-Lovejoy D, Yi J, et al. 2012. Catalytic site remodelling of the DOT1L methyltransferase by selective inhibitors. Nat Commun 3: 1288.

Yun M, Wu J, Workman JL, Li B. 2011. Readers of histone modifications. Cell Res 21: 564-578.

Zhang W, Xia X, Reisenauer MR, Hemenway CS, Kone BC. 2006. Dotla-AF9 complex mediates histone H3 Lys-79 hypermethylation and repression of $E N a C \alpha$ in an aldosterone-sensitive manner. J Biol Chem 281: 18059-18068.

Zhang Y, Mittal A, Reid J, Reich S, Gamblin SJ, Wilson JR. 2015. Evolving catalytic properties of the MLL family SET domain. Structure 23: 1921-1933.

Ziemin-van der Poel S, McCabe NR, Gill HJ, Espinosa RIII, Patel Y, Harden A, Rubinelli P, Smith SD, LeBeau MM, Rowley JD, et al. 1991. Identification of a gene, $M L L$, that spans the breakpoint in 11q23 translocations associated with human leukemias. Proc Natl Acad Sci 88: 1073510739.

Zuber J, Shi J, Wang E, Rappaport AR, Herrmann H, Sison EA, Magoon D, Qi J, Blatt K, Wunderlich M, et al. 2011. RNAi screen identifies Brd4 as a therapeutic target in acute myeloid leukaemia. Nature 478: 524-528. 


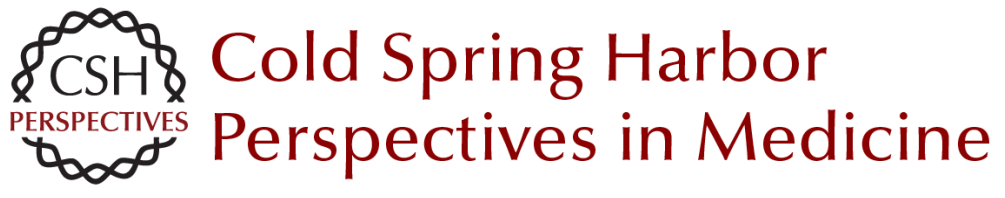

\section{Mixed-Lineage Leukemia Fusions and Chromatin in Leukemia}

Andrei V. Krivtsov, Takayuki Hoshii and Scott A. Armstrong

Cold Spring Harb Perspect Med 2017; doi: 10.1101/cshperspect.a026658 originally published online February 27, 2017

\section{Subject Collection Chromatin Deregulation in Cancer}

Mixed-Lineage Leukemia Fusions and Chromatin in Leukemia

Andrei V. Krivtsov, Takayuki Hoshii and Scott A. Armstrong

Targeting Cancer Cells with BET Bromodomain Inhibitors

Yali Xu and Christopher R. Vakoc

The Role of Nuclear Receptor-Binding SET

Domain Family Histone Lysine Methyltransferases

in Cancer

Richard L. Bennett, Alok Swaroop, Catalina Troche, et al.

SETting the Stage for Cancer Development:

SETD2 and the Consequences of Lost Methylation Catherine C. Fahey and lan J. Davis

ATRX and DAXX: Mechanisms and Mutations Michael A. Dyer, Zulekha A. Qadeer, David Valle-Garcia, et al.

DNMT3A in Leukemia

Lorenzo Brunetti, Michael C. Gundry and Margaret A. Goodell

Oncogenic Mechanisms of Histone H3 Mutations Daniel N. Weinberg, C. David Allis and Chao Lu

Nonhistone Lysine Methylation in the Regulation of Cancer Pathways

Scott M. Carlson and Or Gozani
TET2 in Normal and Malignant Hematopoiesis Robert L. Bowman and Ross L. Levine

Long Noncoding RNAs: At the Intersection of Cancer and Chromatin Biology Adam M. Schmitt and Howard Y. Chang

DNA Hypomethylating Drugs in Cancer Therapy Takahiro Sato, Jean-Pierre J. Issa and Patricia Kropf

The Chromodomain Helicase DNA-Binding Chromatin Remodelers: Family Traits that Protect from and Promote Cancer Alea A. Mills

Exploitation of EP300 and CREBBP Lysine

Acetyltransferases by Cancer Narsis Attar and Siavash K. Kurdistani

Histone Lysine Demethylase Inhibitors Ashwini Jambhekar, Jamie N. Anastas and Yang Shi

Cohesin Mutations in Cancer Magali De Koninck and Ana Losada

MLL3/MLL4/COMPASS Family on Epigenetic Regulation of Enhancer Function and Cancer Christie C. Sze and Ali Shilatifard

For additional articles in this collection, see http://perspectivesinmedicine.cshlp.org/cgi/collection/ 